\title{
A Case of an AUPBD Treated by Drainage of Major Papilla
}

\author{
Min Hee Kim, Jae Kwang Lee, Hyun Soo Kim, In Park, Jin Kyung Park, Dae Myung Oh, Jae Hyun Ha \\ Division of Gastroenterology and Hepatology, Department of Internal Medicine, Daegu Fatima Hospital, Daegu, Korea
}

Anomalous union of the pancreaticobiliary duct (AUPBD) is a rare congenital anomaly, defined as the pancreaticobiliary ductal union located outside of the duodenal wall, usually forming a markedly long common channel. This anomaly is associated with congenital choledochal cyst, carcinoma of the biliary tract and pancreatitis, and is more commonly seen in Asian than in Western countries. AUPBD is frequently accompanied by biliary dilatation, but some patients with AUPBD have no biliary dilatation. The causal relationship between AUPBD and biliary dilatation associated with this anomaly has not been fully established. Here, we report a case of type IIIC2 AUPBD without biliary duct dilatation that was treated by drainage of major papilla.

Korean J Pancreas Biliary Tract 2018;23(2):71-75

Keywords: Bile ducts, Pancreatic ducts, Choledochal cyst, Sphincterotomy $\begin{array}{lr}\text { Received } & \text { Dec. 1, 2017 } \\ \text { Revised } & \text { Jan. 10, } 2018 \\ \text { Accepted } & \text { Jan. 11, 2018 }\end{array}$

Corresponding author : Jae Kwang Lee

Division of Gastroenterology and Hepatology Department of Internal Medicine, Daegu Fatima Hospital, 99 Ayang-ro, Dong-gu, Daegu 41199, Korea Tel. +82-53-940-7191 Fax. +82-53-954-7417 E-mail; ljkvic33@naver.com

\section{서 론}

췌담관 합류 이상 (anomalous union of pancreaticobiliary duct, AUPBD)은 매우 드문 선천성 기형으로 발생학적으로 췌 관과 총수담관의 합류가 십이지장 벽 외부에서 이루어져 공 통관이 비정상적으로 길어지는 질환이다. ${ }^{1}$ 이로 인해 담췌관 이 오디 괄약근의 조절 영역에서 벗어나게 되어 췌액과 담즙 의 상호 역류가 일어나고 이러한 췌액과 담즙의 역류로 인해 담관 낭종, ${ }^{2}$ 췌장염 ${ }^{3}$ 및 담관암, 담낭암과 같은 악성 종양 ${ }^{4}$ 또 한 발생할 수 있는 것으로 알려져 있다. 한편 분할췌는 췌장에 서 발생하는 흔한 선천성 기형으로 태생 2 개월째 복측 췌관과
배측 췌관의 융합 실패로 발생하고 이에 따라 췌액이 주유두 와 부유두를 통해 각각 십이지장으로 배출된다. 이때 상대적 으로 많은 양의 췌액이 작은 직경을 가진 부유두 개구부를 통 해 배출됨으로써 췌액의 저류가 발생하게 되어 반복적인 췌 장염의 원인이 될 수 있는 것으로 알려져 있다.

저자들은 우상복부 통증을 주소로 내원한 35세 여자 환자 에서 내시경적 역행성 담췌관 조영술(endoscopic retrograde cholangiopancreatography, ERCP)을 통하여 담관 낭종이 없 는 췌담관 합류 이상과 동반된 불완전 분할췌를 진단 하였으 며 주유두 괄약근 절개술(major papilla sphincterotomy)로 증 상이 호전되고 이후 재발하지 않은 1 예를 경험하였기에 문헌 
고찰과 함께 보고하는 바이다.

\section{증 례}

35 세 여자가 우상복부 통증을 주소로 내원하였다. 내원 1일 전부터 발생한 우상복부의 지속적인 통증으로 타 병원 방문 후 본원으로 전원되었으며 본원 방문 당시 통증의 정도는 경 미하였고 소화불량이나 구토, 황달이 동반되어 있지는 않았다. 과거력 및 가족력에 특이사항은 없었다. 혈압은 $110 / 70 \mathrm{mmHg}$, 맥박수는 65 회/분, 호흡수 17 회/분, 체온 $36.6^{\circ} \mathrm{C}$ 로 활력징후 는 안정되어 있었다. 신체 검진상 공막 황달 소견은 없었고 복 부 압통 및 반발 압통 또한 동반되지 않았다. 타 병원에서 내원 1 일 전 시행한 말초혈액 검사에서 $\mathrm{WBC} 9,170 / \mathrm{mm}^{3}(4,400-$ 11,000), AST 656 IU/L (19-48), ALT 303 IU/L (13-40), ALP $278 \mathrm{IU} / \mathrm{L}$ (40-130), total bilirubin $1.75 \mathrm{mg} / \mathrm{dL}(0.1-1.2)$ 로 간 기능 이상 소견을 보였고, amylase 134 IU/L (0-90), lipase 291 IU/L (13-60)로 증가되어 있었다. 본원 내원하여 시행한 말초

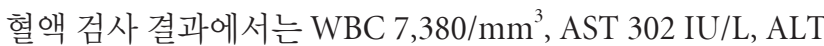
264 IU/L, ALP 90 IU/L, r-GTP 254 IU/L (4-63), total bilirubin $1.64 \mathrm{mg} / \mathrm{dL}$, direct bilirubin $0.27 \mathrm{mg} / \mathrm{dL}(0-0.3)$ 로 호전 소견 을 보였다. 이외 amylase $96 \mathrm{IU} / \mathrm{L}$, lipase $94 \mathrm{IU} / \mathrm{L}$ 로 호전 소견 이 함께 관찰되었다. 복통의 원인을 감별하기 위해 복부 컴퓨 터단층촬영(computed tomography, CT)을 시행하였으며 담 관과 췌관의 비정상적인 확장이나 담관 결석은 관찰되지 않 았고 담낭 내에서도 뚜렷한 담석이나 담낭벽의 비후는 보이
지 않았다(Fig. 1). 제2병일에 시행한 말초혈액 검사상 AST $62 \mathrm{IU} / \mathrm{L}$, ALT $141 \mathrm{IU} / \mathrm{L}$, total bilirubin $1.27 \mathrm{mg} / \mathrm{dL}$, amylase $49 \mathrm{IU} / \mathrm{L}$, lipase $52 \mathrm{IU} / \mathrm{L}$ 로 내원 시에 비하여 호전 추세에 있었 으며 우상복부 통증 또한 더 이상 호소하지 않았다. 총담관결 석에 의해 총담관폐쇄가 유발된 후 자연적으로 담관결석이 배출되었을 가능성을 염두에 두고 내시경 초음파 검사를 시 행하였고, 검사 결과 총담관의 직경은 $4.8 \mathrm{~mm}$ 로 관찰되었으 며 담관결석 및 담낭결석은 보이지 않았다. 바터 팽대부 (ampulla of Vater) 또한 정상 소견을 보였다. 검사상 명확한 이상 소견이 없었고 환자 복통이 호전되어 식이를 시작하였으나 식이 후 오후 9 시경 다시 복통이 발생하였고 말초혈액 검사 결 과 AST $340 \mathrm{IU} / \mathrm{L}$, ALT $234 \mathrm{IU} / \mathrm{L}$, total bilirubin $1.75 \mathrm{mg} / \mathrm{dL}$, amylase $361 \mathrm{IU} / \mathrm{L}$, lipase $96 \mathrm{IU} / \mathrm{L}$ 로 증가 소견을 보여 다시 금 식을 시행하였다. 금식 후 다음 날 제 3 병일 아침 경 복통은 자 연적으로 호전되었다. 본원에서 시행한 영상 검사에서는 특 이 소견이 없었으며 식이 후 발생하는 특징적인 담도성 동통 및 그에 동반된 간기능 이상 소견으로 type 2 의 오디괄약근 기 능이상에 의한 통증 가능성 고려하여 내시경적 역행성 담췌 관 조영술 및 내시경 주유두부 괄약근 절개술을 계획하였다. 내시경적 역행성 담췌관 조영술시 주유두부를 통하여 조영제 를 주입하였을 때 복측 췌관과 총담관이 동시에 조영되었고 총담관과 복측 췌관이 십이지장벽 바깥에서 합류하여 $15 \mathrm{~mm}$ 이상의 긴 공통관을 형성하고 있었으며 조영제를 계속 주입 시, 복측 췌관과 배측 췌관의 합류가 있는 불완전 분할췌를 보 였다(Fig. 2A). 풍선도관(retrieval balloon)을 이용하였으나
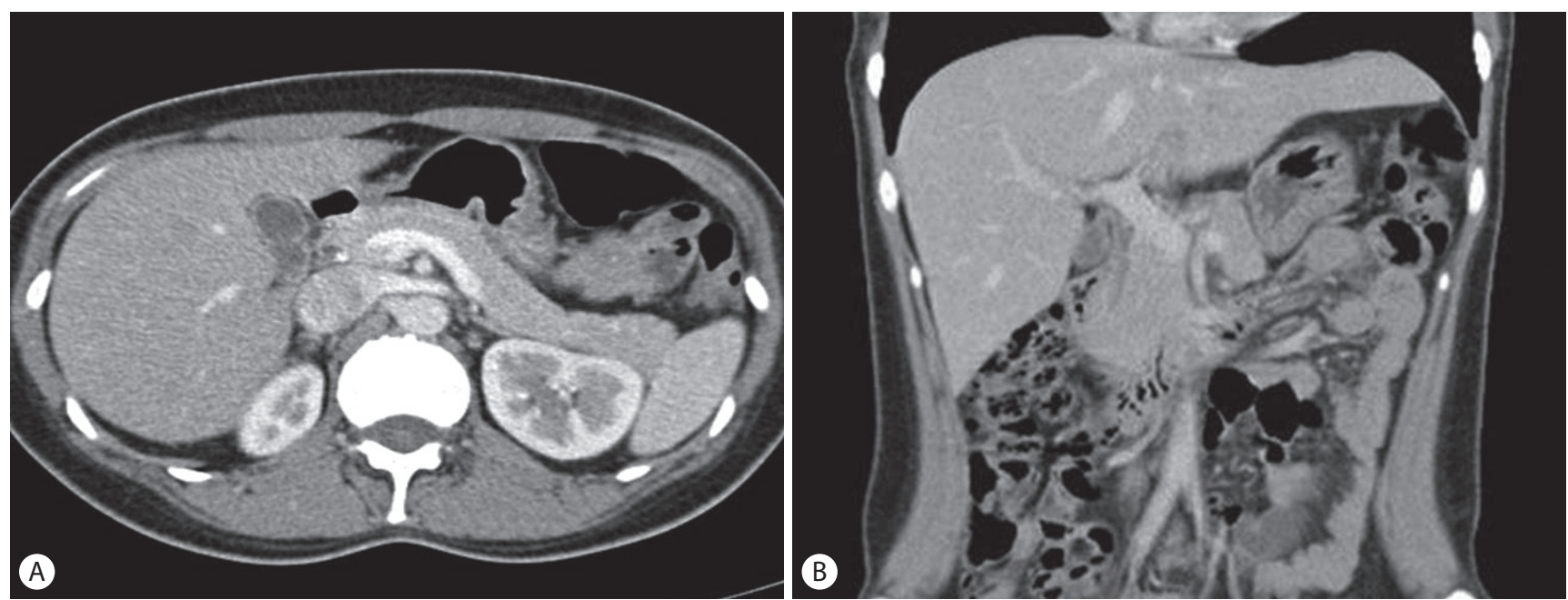

Fig. 1. Computed tomography (CT) image (A) and (B) showed no visible abnormal dilataion or high attenuation stone in biliary tract and pancreatic duct. 

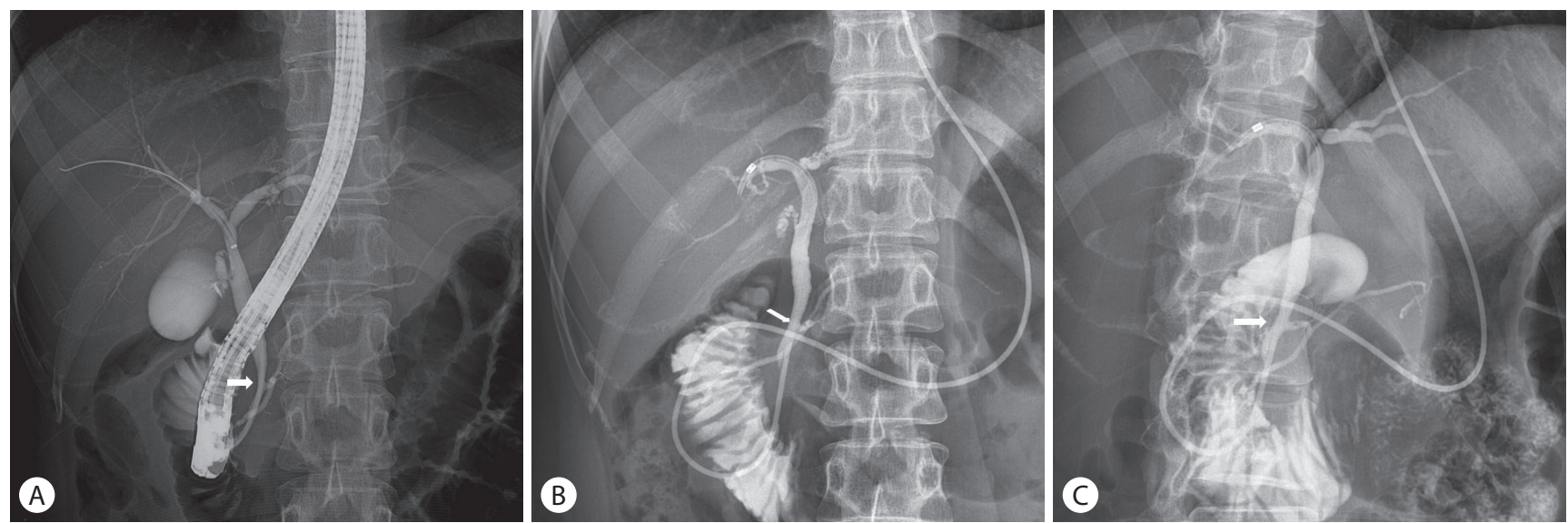

Fig. 2. Arrows indicate the connection between common bile duct and the main pancreatic duct which was located outside the duodenal wall. (A) When contrast was injected through the major papilla, common bile duct and part of pancreatic duct were simultaneously visualized. Also, the contrast was continuously injected, incomplete pancreatic divisum with confluence of main duct and accessory duct was visualized. After ENBD insertion, image (B) and (C) showed that AUPBD and incomplete pancreatic divisum were reconfirmed. ENBD, endoscopic nasobiliary drainage; AUPBD, anomalous union of the pancreaticobiliary duct.

발견되는 담관결석은 없었고 담즙의 배액을 위해 주유두부 괄 약근 절개술을 시행 후 내시경적 경비담도 배액관(endoscopic nasobiliary drainage, ENBD)을 유치하였다. 시술 종료시 촬 영한 담췌관 조영사진에서 췌담관 합류 이상과 불완전 분할 췌가 재확인되었다(Fig. 2B, C). 제4병일에 시행한 말초혈액 검사상 AST $98 \mathrm{IU} / \mathrm{L}$, ALT $221 \mathrm{IU} / \mathrm{L}$, total bilirubin $1.25 \mathrm{mg} / \mathrm{dL}$, amylase $108 \mathrm{IU} / \mathrm{L}$, lipase $39 \mathrm{IU} / \mathrm{L}$ 로 감소 소견을 보여 다시 단 계적 식이를 시작하였다. 제6병일에 시행한 말초혈액 검사상 AST $20 \mathrm{IU} / \mathrm{L}$, ALT $120 \mathrm{IU} / \mathrm{L}$, total bilirubin $1.34 \mathrm{mg} / \mathrm{dL}$, amylase $45 \mathrm{IU} / \mathrm{L}$, lipase $34 \mathrm{IU} / \mathrm{L}$ 로 호전을 보였으며 식이를 지속 중에도 복통은 없었다(Fig. 3). 제8병일에 증상 없이 퇴원하였 으며 이후 외과에서 복강경담낭절제술을 시행하였고 병리조 직 검사상 특이사항은 없었다. 환자는 현재까지 14 개월째 증 상 재발 없이 추적관찰 중이다.

\section{고 찰}

췌담관 합류 이상은 십이지장 벽 외부에서 췌관과 담관의 합류가 이루어지는 선천성 기형이다. Kimura 등은 췌관이 총 담관에 합류하는 I형(P-C union)과 총담관이 췌관으로 합류 하는 II형(C-P union)으로 분류하였고, 새로 제시된 Komi 분 류에 따르면 I형은 총담관과 췌관이 거의 직각으로 만나는 경 우, II형은 총담관과 췌관이 예각으로 만나는 경우, III형은 췌 관과 총담관의 말단부위 및 부췌관의 복합 합류 이상을 보이 는 경우로 분류하였다. ${ }^{5}$ 본 증례의 경우는 Kimura 분류 I형,

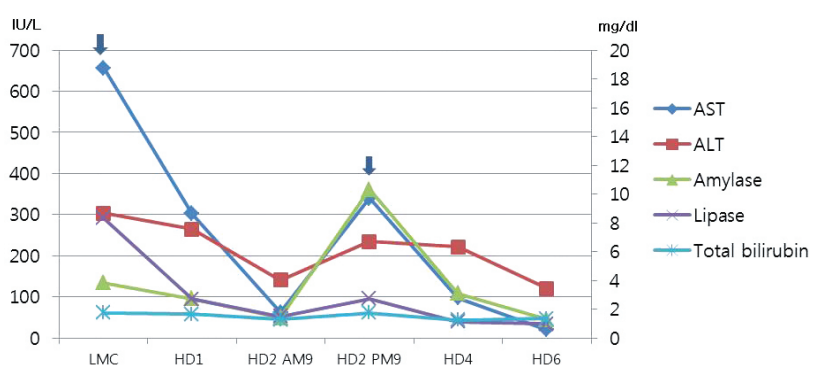

Fig. 3. Arrows indicate when abdominal pain developed. LMC, local medical center; HD, hospital day.

Komi 분류 III형에 해당되며 주췌관과 부췌관의 합류가 있으 면서 확장 소견이 뚜렷이 관찰되지는 않아 Komi 분류 IIIc2에 해당된다고 볼 수 있으나 담관 확장이 동반되지 않아 Komi 분 류에 절대적으로 부합하지는 않는다. 담관 낭종은 췌담관 합 류 이상의 $70 \%$ 정도에서 관찰되지만, 본 증례의 경우처럼 담 관 확장이 동반되지 않는 경우도 있어 췌담관 합류 이상이 담 관 낭종의 원인이라고 단정 지을 수는 없다. ${ }^{6}$

정상적인 경우에서는 췌관내 압력이 담도 내압보다 높아도 오디 괄약근에 의해 췌액의 담도내 역류가 방지되지만, 췌담 관 합류 이상의 경우에서는 췌장액이 담도 내로 유입되는 것 을 허용하게 된다. 반복적이고 지속적인 췌장액의 담도 내 유 입으로 담관 내의 점막을 파괴하고 섬유화를 일으키며 이것 이 결국 담도 내압의 상승을 초래하여 반복적인 담관염, 담관 의 낭종성 확장, 담도암 또는 담낭암을 유발하게 된다. 또한 담도 내압이 상승하여 담즙이 췌장으로 유입되어 반복적인 
췌장염이나 췌장암의 원인이 될 수 있다. 담낭암의 약 $10 \%$ 에 서 췌담관 합류 이상이 발견되고 췌담관 합류 이상이 있는 환 자의 $15-40 \%$ 에서 담관계 종양이 발생하는 것으로 보고되고 있으며 췌담관 합류 이상은 담관 낭종이나 낭성확장의 동반 유무와 관계없이 종양의 위험을 증가시키는 것으로 알려져 있다. ${ }^{7-9}$ 이러한 종양의 발생은 담낭이나 담관 낭종 등 담즙이 오래 저장되는 장소에서 잘 일어난다고 한다. 담관 낭종이 동 반된 경우에는 담낭이 위축되어 있는 경우가 많아 담즙의 담 낭내 유입이 충분하지 않으며, 담관 내로 역류된 췌액이 주로 확장된 담관 내에 존재하여 담낭 내에는 비교적 미치는 영향 이 적다. 반면에 담관 낭종이 동반되지 않은 췌담관 합류에서 는 담관 내로 역류된 췌액이 쉽게 담낭 내로 역류되어 담낭 상 피의 변화를 주로 일으킨다고 한다. ${ }^{910}$ 따라서 담관 낭종이 동 반된 췌담관 합류 이상 환자에서는 낭종 내에서, 담관 낭종이 동반되지 않은 췌담관 합류 이상 환자에서는 담낭 내에서 악 성 종괴가 호발하는 것으로 알려져 있다. ${ }^{3,10}$ 본 증례에서는 담 관 낭종이 동반되지 않았으며 담낭암의 발생 가능성이 높아 예방적 담낭절제술을 시행하였다.

분할췌(pancreas divisum)는 췌장에서 발생하는 가장 흔한 선천성 기형으로 태생기에 복측 췌관과 배측 췌관의 융합 실 패로 췌액이 주유두와 부유두를 통해 각각 십이지장으로 배 출된다. 이때 상대적으로 직경이 작은 부유두 개구부를 통해 대부분의 췌액이 배출됨으로써 분할췌를 가진 사람의 일부에 서 췌장염이 반복적으로 발생하는 것으로 알려져 있다. 분할 췌는 내시경적 역행성 담췌관 조영술로 진단할 수 있으며 주 유두부를 통해 조영제를 주입하였을 때 췌관이 보이지 않거 나, 작은 복측 췌관만이 조영된다. 부유두부를 통해 조영하였 을 때 배측 췌관과 복측 췌관 사이에 연결이 없을 때 확진할 수 있으며 불완전 분할췌의 경우 가느다란 연결이 있을 수 있다. ${ }^{4}$ 본 증례에서는 내시경적 역행성 담췌관 조영술에서 긴 공통관 을 보이는 췌담관 합류 이상과 작은 복측 췌관만 관찰되어 분 할췌를 함께 진단할 수 있었다.

본 증례의 경우 내원 전 타 병원 방문 당시 및 본원 입원 2일 째 복통이 발생하였으며 2번의 복통 모두 복통 발생 후 특별 한 조치 없이 증상이 완전히 호전되었고 복통 발생 당시 시행 한 타 병원 및 본원의 혈액 검사에서 간기능 검사상 이상 및 혈청 amylase 및 lipase의 상승이 함께 발생하는 임상양상을 보였다. 비록 오디괄약근 압력 검사(sphincter of Oddi manometry) 등의 추가적인 검사를 시행하지는 못하였지만, 췌담관 합류 이상으로 인하여 담즙과 췌액이 공통관을 통하여 배출
되므로 공통관의 오디괄약근 기능 이상이 있을 경우 담도성 오디괄약근 기능 이상 및 췌장성 오디괄약근 기능 이상의 증 상 및 검사 소견이 함께 나타날 수 있고, 따라서 간기능 검사 상 이상 및 혈청 amylase 및 lipase의 상승이 모두 동반된 것으 로 판단하였다. 내시경적 주유두부 괄약근 절개술을 실시하 였고 이후 췌담관 합류 이상과 분할췌와 같은 구조적인 이상 은 여전히 남아있는 상태이나 기능적으로 담즙과 췌액의 정 상적인 배출을 가능하게 하여 증상의 재발 없이 호전된 것으 로 보인다. 그리고 본 증례에서 비록 혈청 amylase 및 lipase의 상승과 함께 분할췌가 동반되어 있었으나, 혈액 검사에서 간 기능 검사상 이상 소견이 함께 보였으며 증상이 갑작스럽게 발 생하였다가 호전되었고 부유두부가 아닌 주유두부 괄약근 절 개술을 시행 후 재발 없이 호전된 점을 고려하였을 때 분할췌 로 인한 급성 췌장염의 가능성은 상대적으로 낮다고 판단된다.

췌담관 합류 이상은 드문 질환이며 진단이 간단하지 않아 간과될 수 있으므로 담관염이나 췌장염의 증상을 호소하는 환자에서 내시경적 역행성 담췌관 조영술이나 자기공명 담췌 관 촬영술 등을 시행하여 췌담관 합류 이상과 분할췌의 유무 를 확인해야 하며, 진단 되었을 경우 담낭암 또는 담도암을 예 방하기 위한 적극적인 조치가 필요하다.

\section{요 약}

췌담관 합류 이상은 췌관과 총수담관의 합류가 십이지장 벽 외부에서 이루어지고 공통관이 비정상적으로 길어지는 선 천성 기형이다. 이로 인해 오디괄약근의 지배를 받지 않아 췌 액과 담즙의 상호 역류가 일어나고 담관 낭종, 담석, 담관염, 췌장염 등의 합병증과 담관암, 담낭암과 같은 악성 종양이 발 생할 수 있다고 알려져 있다. 분할췌는 태생기에 복측 췌관과 배측 췌관의 융합 실패로 발생하고 췌액이 주유두와 부유두 를 통해 각각 십이지장으로 배출되며 상대적으로 많은 양의 췌액이 직경이 작은 부유두 개구부를 통해 배출됨으로써 췌액 의 저류가 발생하게 되어 췌장염이 반복적으로 발생하는 원 인이 될 수 있다. 본 증례는 우상복부 통증을 주소로 내원한 35 세 여자 환자로 내시경적 역행성 담췌관 조영술을 통하여 담관 낭종이 없는 췌담관 합류 이상과 동반된 불완전 분할췌 를 발견하여 보고하는 바이다.

국문 색인: 췌담관 합류 이상, 불완전 분할췌, 담관 낭종, 내 시경적 유두부 괄약근 절개술 


\section{Conflicts of Interest}

The authors have no conflicts to disclose.

\section{REFERENCES}

1. Kamisawa $T$, Ando $H$, Hamada $Y$, et al. Diagnostic criteria for pancreaticobiliary maljunction 2013. J Hepatobiliary Pancreat Sci 2014;21:159161.

2. Lipsett PA, Pitt HA, Colombani PM, Boitnott JK, Cameron JL. Choledochal cyst disease. A changing pattern of presentation. Ann Surg 1994;220:644-652.

3. Misra SP, Dwivedi M. Pancreaticobiliary ductal union. Gut 1990;31:11441149.

4. Kimura K, Ohto M, Saisho H, et al. Association of gallbladder carcinoma and anomalous pancreaticobiliary ductal union. Gastroenterology 1985;89:1258-1265.

5. Komi N, Takehara H, Kunitomo K, Miyoshi Y, Yagi T. Does the type of anomalous arrangement of pancreaticobiliary ducts influence the sur- gery and prognosis of choledochal cyst? J Pediatr Surg 1992;27:728731.

6. Mori K, Akimoto R, Kanno M, Kamata T, Hirono Y, Matsumura A. Anomalous union of the pancreaticobiliary ductal system without dilation of the common bile duct or tumor: case reports and literature review. Hepatogastroenterology 1999;46:142-147.

7. Nomura T, Shirai Y, Wakai T, Yokoyama N, Sakata J, Hatakeyama K. Narrow portion of the terminal choledochus is a cause of upstream biliary dilatation in patients with anomalous union of the pancreatic and biliary ducts. World J Gastroenterol 2005;11:6503-6507.

8. Elnemr A, Ohta $T$, Kayahara $M$, et al. Anomalous pancreaticobiliary ductal junction without bile duct dilatation in gallbladder cancer. Hepatogastroenterology 2001;48:382-386.

9. Sugiyama M, Abe N, Tokuhara M, Masaki T, Mori T, Atomi Y. Pancreatic carcinoma associated with anomalous pancreaticobiliary junction. Hepatogastroenterology 2001;48:1767-1769.

10. Nagata E, Sakai K, Kinoshita H, Hirohashi K. Choledochal cyst: complications of anomalous connection between the choledochus and pancreatic duct and carcinoma of the biliary tract. World J Surg 1986;10:102110. 